\title{
Black Cumin Seeds Extract Increase Lymphocyte Activity in IFN- $\gamma$ Secretion in Sprague Dawley Rat (SD) Induced by Dimethylbenzantracene
}

\author{
Akrom $^{1 *}$, Titiek Hidayati ${ }^{2}$, Sagiran $^{3}$, Indrayanti $^{4}$ \\ ${ }^{1}$ Pharmacology and Clinical Pharmacy Department, Universitas Ahmad Dahlan, Yogyakarta Indonesia \\ ${ }^{2}$ Community and Family Medicine Department, Medicine and Health Science Faculty, Universitas Muhammadiyah \\ Yogyakarta, Yogyakarta, Indonesia \\ ${ }^{3}$ Surgeon Department, Medicine and Health Science Faculty, Universitas Muhammadiyah Yogyakarta, Yogyakarta, \\ Indonesia \\ ${ }^{4}$ Pathology Anatomy Department, Medicine and Health Science Faculty, Universitas Muhammadiyah Yogyakarta, \\ Yogyakarta, Indonesia
}

\begin{abstract}
Interferon-gamma (IFN- $\gamma$ ) is one of the central cytokines in the anti-carcinogenesis immune response. Black cumin seeds (BCS) have an active content of thymoquinone and unsaturated fatty acids with biological activity as immunomodulators. This study aimed to determine the effect of administration of BCS extract on IFN- $\gamma$ secretion activity by DMBA-induced SD rat lymphocytes. In vivo experimental study on DMBA-induced SD rats, BCS extract was given with three doses for two weeks before being induced and five weeks during DMBA induction. IFN- $\gamma$ levels in lymphocyte culture supernatants were determined by the ELISA method. The difference in IFN- $\gamma$ levels between groups was analyzed by ANOVA test, the significance of $95 \%$. The results showed that administration of BCS extract for 14 days did not affect cellular composition toward the edge of the test animal. BCS extract can increase IFN- $\gamma$ secretion activity by DMBA-induced SD rat lymphocytes.
\end{abstract}

Keywords: black cumin seed, IFN-y; DMBA: immunomodulator, carcinogenesis.

\section{INTRODUCTION}

The immune system with immunosurveillance is a vital component that is responsible for the development of cancer of a neoplastic cell (Dembic, 2015; Disis, 2010; American Cancer Society, 2016; Li, et al., 2019). The development of proto-oncogenes into cancerous oncogenes that are evolutionarily is thought to be one of them caused by a decrease in the ability of the host immunosurveillance (Baj-Krzyworzeka, et al., 2004)
(Ballestero Fêo, et al., 2018). The host's response to cancer is a complex mechanism, involving components of the regulatory system, phagocyte effector activity and immune system mediators (Hayakawa, et al., 2002) (Ren, et al., 2019; Selinger, et al., 2018; Upadaya, et al., 2018). Interferon-

Submitted: September 12, 2019

Revised: October 14, 2019

Accepted: October 14, 2019

*Corresponding author: akrom@pharm.uad.ac.id 
gamma (IFN- $\gamma)$ is one of the anti-carcinogenesis pro-inflammatory cytokines, is one of the regulatory system immune response, due to exposure to dimethylbenzanthracene (Castro, et al., 2018). Unfortunately, until now, it has not been widely studied, primarily when associated with immunogens from plants that have the potential as immunomodulators and also as chemopreventives (Dunn, et al., 2004; Zekri, et al., 2018; Li, et al., 2002).

One of the plants that empirically and laboratory has been used as chemopreventive as well as immunomodulators is black cumin seed (BCS) or Nigella Sativa (Shaterzadeh-Yazdi, et al., 2018; Hidayati, et al., 2019; Badr, et al., 2011; Randhawa, et al., 2011; Soliman, et al., 2017). Nigella sativa seeds (N.sativa) contain various active compounds which are thought to be immunomodulatory as well as cancer chemopreventives (El-Mahmoudy, et al., 2002). Mousa (2004) proved that BCS could provide chemopreventive effects in vivo in DMBA-induced mice carcinogens (Mousa, et al., 2004). BCS administration for 14 days in mice induced with 7,12-di-methylbenz(a)anthracene (DMBA) reduces tumor markers and increases TNF $\alpha$ levels as a factor driving DNA apoptosis and fragmentation (Odhaib, et al., 2018). In Swiss mice- infected plasmodium berghei (P.berghei), the ethanolic extract of BCS was shown to increase the phagocytic activity of macrophages (Hidayati, 2006). Administration of BCS oil in mice induced with streptozotocin has been shown to increase phagocytosis of peritoneal macrophages (Fajar, et al., 2017). Immunomodulatory activity of the BCS can optimize the immune response to foreign substances or antigens, including neoplasmic antigens (el Aziz, 2005; Gholamnezhad, et al., 2019; (Hidayati, et al., 2017).

DMBA compounds are genotoxic and immunotoxic. Genotoxic indirectly from DMBA has a mechanism through cytochrome P450-mediated enzymatic or biotransformation activation and glutathione-S-transferase activity (Parmar, et al., 2011). These conversions produced electrophilic, which can react with several nucleophilic compounds in proteins, DNA, and RNA. Cancer cells start on the occurrence of mutations of protooncogene into oncogenes (Barletta, et al., 2004). The variation in the p53 gene will lead the mutant cells to avoid the mechanism of apoptosis so that it will stay alive and develop into cancer cells (Gao, et al., 2008). Neoplastic cells will be recognized as non-self by the immune system, which will then generate an immune response. Peptides from $\mathrm{H}$-ras gene mutations induce $\mathrm{T}$ cell proliferation in vitro. Single-point mutations in oncogenic H-Ras and p53 genes trigger tumors with the potential to form T-cell specific epitopes. Activation of cellular immune responses through the CD4 T cells increase the phagocytic activity of effector cells (CTL, macrophages, and NK cells) and increase the production of cellular immune response regulators, among others, IFN- $\gamma$, TNF $\alpha$ and IL-2. The immune system as a body surveillance system will prevent neoplastic cells towards tumor tissue formation and subsequent carcinogenesis (Soliman, et al., 2017) (Ren, et al., 2018).

Black cumin seeds are empirically, laboratories and clinically proven to be safe, and tolerable (Akrom, et al., 2017) (Rachman, et al., 2017). The administration of BCS is thought to increase the immune response in neoplasms (Akrom, et al., 2017; Al Ghamdi, 2002. From previous studies it has been proven that administration of BCS oil in Balb c mice infected with cytomegalovirus has been shown to prevent infection and increase IFN- $\gamma$ levels and CD4 number and activity (Shaterzadeh-Yazdi, et al., 2018). Administration of BCS ethanol extract has been shown to be effective in inhibiting carcinogenesis and improving immune responses (Hidayati, et al., 2006; Randhawa, et al., 2011). The administration of BCS ethanolic extracts in doses of $250 \mathrm{mg} / \mathrm{kg} \mathrm{BW}$ was proven to be able to inhibit carcinogenesis (Fathy, 2013). IFN- $\gamma$ is a pleiotropic anti-carcinogenesis cytokine and plays an important role in regulating the anti-carcinogenesis immune response. IFN- $\gamma$ is associated with antiproliferative, pro-apoptotic, and antitumor mechanisms (Ren, et al., 2019). Until now how the effect 
of BCS ethanolic extract on IFN- $\gamma$ levels in SD rats induced by DMBA has not been studied. Black cumin seed (BCS) is expected to increase IFN- $\gamma$ secretion activity by lymphocyte of DMBA-induced $\mathrm{SD}$ rats. The purpose of this study was to determine the effect of BCS administration to IFN- $\gamma$ secretion activity of DMBA-induced SD mice lymphocytes.

\section{METHODS}

This study was an experimental laboratory with the control group. Test animals were divided into seven groups randomly, group one as a healthy control group (solvent group), group two as a sick control group (DMBA group), group three to five as the treatment groups, group six as Imboost group (positive control group 1), and group seven as a tamoxifen group (positive control group 2). The study protocol has been reviewed and declared ethically viable by the research ethics committee of Universitas Ahmad Dahlan, Yogyakarta, Indonesia (No. 043/KEP-UAD/II/2019).

\section{Animal, Material and Equipment}

The study was conducted at the animal breeding and experimental unit of Gadjah Mada University. We used 7,12 dimethylbenzanthracene (DMBA, Sigma-Aldrich, St Louis, USA) for inducing carcinogenesis. We obtained a DMBA from one of the official distributors in Yogyakarta. We used corn oil as solvent DMBA, as in previous studies (Hidayati, et al., 2019). Sprague Dawley (SD) rat test animals were obtained from the Animal Breeding and Experimental Unit, Gadjah Mada University. We used 105 female SD rats strain, aged 14-30 days with an average weight of 60-80 g. A twenty one female SD rats are for the preliminary test, and 84 are for the examination of BCS preparation. The BCS preparation is ethanolic extract of BCS. Ethanol extract of BCS has been provided by the Department of Pharmaceutical Biology, Pharmacognition and Phytochemistry, Faculty of Pharmacy, Ahmad Dahlan University. "Imboost" preparations, one of the immunomodulatory preparations and have obtained a marketing authorization from the Republic of Indonesia drug and food control agency, were obtained by prescription from a pharmacy, as positive control 1. Tamoxifen citrate (Nolvadex), a preparation for chemotherapy in breast cancer patients in Indonesia, is used as a positive control 2. Tamoxifen is obtained from a pharmacy using a prescription from a doctor. We used an IFN- $\gamma$ (Quantikine, R \& D system, Inc. Minneapolis, USA) elisa kit to determine IFN- $\gamma$ levels in the supernatant culture of limpocytes.

\section{Experimental Procedure}

Test animals with age as needed, after ensuring their health by trained personnel, then weighed in order to obtain test animals in accordance with the criteria. Test animals are then placed in plastic cages. During the experiment the test animals were kept at the appropriate temperature and humidity of the room, had adequate lighting and got standard food and drink. Test animal care is carried out by certified trained personnel in the Unit of care and breeding of test animals, Gajah Mada University. Test animals are acclimatized for one week before being used for experiments.

Test animals were divided into seven groups randomly, twelve animals each group.. Group one as solvent group, during the trial period the test animals get additional treatment viz $1 \times 0.5$ $\mathrm{ml} /$ day per oral of corn oil, but without inducing DMBA. Group two as a DMBA (sick) group, In the first two weeks of the experimental period the test animals have not received additional treatment, starting form third week of experimental perode the test animals were given preparations containing DMBA $20 \mathrm{mg} / \mathrm{kg} \mathrm{BW}$ in $0.5 \mathrm{ml}$ of solvent corn oil given $2 \mathrm{x} /$ week per peritoneal for five weeks. All test groups, except the solvent group, received DMBA preparations starting from the third week of treatment. Group three to five as the treatment groups, the test animal received BCS preparation in three doses. BCS preparations was carried out start- 
ing from 14 days before the first DMBA administration and continued for five weeks during DMBA administration, i.e. from 4 th weeks of age to $11^{\text {th }}$ weeks of age, $1 \mathrm{x} /$ day orally at doses of 5.25 and 125 $\mathrm{mg} / \mathrm{kgBW} /$ day. BCS preparations were given with three dose ratings based on the results of previous studies (el Aziz, et al., 2005; Karimi, et al., 2011). Group six as Imboost group, the test animals were given immunomodulatory (Imboost) preparations according to the dose in adults who were converted into rat doses. The preparation is given once a day two weeks before DMBA induction and two weeks during the DMBA induction period so that the total administration is four weeks. The preparation company recommends that Imboost be used no more than 4 weeks. Group seven as a tamoxifene group, the preparations was given as the way to administer other preparations, two weeks before DMBA induction and five weeks during DMBA induction. Six-week-old rats were given a DMBA solution in corn oil at a dose of $20 \mathrm{mg} / \mathrm{kg}$ BW orally. DMBA induction was repeated ten times with the frequency of administration twice a week. (Zekri, et al., 2018).

\section{Hemogram and Lymphocyte Activity in se- creting IFN- $\gamma$ Test Procedure}

Hemogram measurements of the animal were carried out 14 days after administration of BCS extract. Blood was isolated from sinus orbitalis by professional trained. We examined hemogram with hemoanalyzer. In the $15^{\text {th }}$ and $50^{\text {th }}$ day, we sacrificed the animal study. The spleen organ was isolated after two and seven weeks administration of BCS preparation and after DMBA induction was completed. Lymphocytes were isolated and cultured following the procedures of previous researchers (Soliman, et al., 2017). IFN- $\gamma$ levels of splenocyte culture supernatants were measured by Enzyme-Linked Immunosorbent Assay (ELISA) sandwiches. The kit used was quantikine M from R \& D System, Inc. Minneapolis, USA. Examination procedures as per the procedures provided by the factory. The test results were read by ELISA reader at a wavelength of $450 \mathrm{~nm}$, IFN- $\gamma$ levels were expressed as $\mathrm{pg} / \mathrm{mL}$.

\section{Data Analysis}

The difference in IFN- $\gamma$ secretion activity by lymphocytes and the average number of blood cells between groups was analyzed by ANOVA, with a confidence level of $95 \%$.

\section{RESULTS}

\section{Hemogram of Experimental Animals}

The results of blood tests after administration of BCS preparations for 14 days showed that there were no changes in the cellular composition of the blood of the test animals, as shown in Table 1.

From table 1, it is known that the administration of BCS for 14 days does not affect the composition of the hemogram. IFN- $\gamma$ secretion lymphocytes activity before and after DMBA induction by the administration of BCS ethanolic extract Lymphocytes are isolated from the spleen organs. Table 2 presents the IFN- $\gamma$ levels that secreted by lymphocyte culture. In this experiment as a baseline is the DMBA group before DMBA induced. Before the DMBA was induced, the DMBA group got standard food and drink. Before the DMBA was induced, the treatment group and the control group received additional treatment according to their group for two weeks besides getting standard food and drink. Research data shows that before being induced by DMBA, the DMBA group and the solvent group had equivalent IFN- $\gamma$ levels, i.e $80 \pm 9$ and $80 \pm 9 \mathrm{pg} / \mathrm{mL}(p>0.05)$. Provision of corn oil for 2 weeks does not affect the activity of lymphocytes in secreting IFN- $\gamma$. In contrast to the solvent group, administration of BCS, thymoquinone and tamoxifen preparations for two weeks increase lymphocyte activity in secreting IFN- $\gamma$. The highest IFN- $\gamma$ level was in the with $125 \mathrm{mg} / \mathrm{kg} \mathrm{BW} /$ day BCS group $(336+49 \mathrm{pg} / \mathrm{mL})$, then followed by a group of $25 \mathrm{mg} / \mathrm{kg} \mathrm{BW} /$ day BCS $(304+15 \mathrm{pg} /$ $\mathrm{mL}$ ) and Imboost group $(291.7+55 \mathrm{p} / \mathrm{mL})$. Before 
induced DMBA, the treatment group and the positive control group had IFN- $\gamma$ levels higher than the IFN- $\gamma$ levels of the solvent and the DMBA group $(p<0.05)$.

The administration of BCS dosages 5, 25, and $125 \mathrm{mg} / \mathrm{kg} \mathrm{BW} /$ day for 14 days increase IF$\mathrm{N}-\gamma$ secretion activity by lymphocytes. The BCS dosage group with a dose of $125 \mathrm{mg} / \mathrm{kg}$ after giving 14 had the highest IFN- $\gamma$ secretion activity, higher than the Imboost and Tamoxifen group but not statistically significant. In eexperimental group, the BCS group with a dose of $5 \mathrm{mg} / \mathrm{kg} \mathrm{BW} /$ day had the lowest IFN- $\gamma$ secretion activity but was higher than the DMBA group and solvent group.

Five weeks administration of corn oil during the DMBA induction period in the solvent group did not affect the lymphocyte activity in secreting IFN- $\gamma$. In the solvent group, IFN- $\gamma$ levels before and after the DMBA induction period were not different $(p>0.05)$. During the DMBA induction period the solvent group received additional treatment that is given corn oil once per day orally.

DMBA induction decreases lymphocyte activity in secreting IFN- $\gamma$. In the DMBA group, the IFN- $\gamma$ levels after induction were lower than before DMBA induced and were statistically significant $(72 \pm 2.7 \mathrm{pg} / \mathrm{mL}$ v.s. $87 \pm 11.2 \mathrm{pg} / \mathrm{mL}, p<0.05$, $p<0.05$ ). Measurement of IFN- $\gamma$ levels after five weeks of induced DMBA, the DMBA group had the lowest level. The IFN- $\gamma$ level of DMBA group was lower than the solvent group $(72 \pm 2.7 \mathrm{pg} / \mathrm{mL}$ v.s. $83 \pm 10.2, p<0.05)$. MBA induction reduced IFN $\gamma$ levels in all experimental groups except the $125 \mathrm{mg} / \mathrm{kg}$ BW BCS group. In the $125 \mathrm{mg} / \mathrm{kg} \mathrm{BW}$ BCS group, IFN- $\gamma$ levels after DMBA induction were higher than before DMBA induced $(690 \pm 54.1$ $\mathrm{pg} / \mathrm{mL}$ v.s. $336+49, p<0.05)$.

Administration of BCS, imboost and tamoxifen preparations increase lymphocyte activity. The research data showed that IFN- $\gamma$ levels in 25 and $125 \mathrm{mg} / \mathrm{kg} \mathrm{BW} \mathrm{BCS}$ groups were higher than IFN- $\gamma$ levels in the Imboost or Tamoxifene group $(p<0.05)$. After the duration of DMBA induction, among the treatment groups, the $125 \mathrm{mg} / \mathrm{kgBW}$ BCS group had the highest IFN- $\gamma$ levels, followed by the $25 \mathrm{mg} / \mathrm{kgBW}$ BCS group, the Imboost group, the $5 \mathrm{mg} / \mathrm{kg} \mathrm{BW}$ BCS group and the lowest is tamoxifene group.

Table I. Composition of blood cells of test animals after obtaining 5, 25, and $125 \mathrm{mg} / \mathrm{kgBW} / \mathrm{day}$ of BCS preparation for two weeks

\begin{tabular}{lcccc}
\hline \multicolumn{1}{c}{ Groups } & $\begin{array}{c}\text { Leukocytes } \\
\left(\mathrm{x} 10^{3}\right)\end{array}$ & $\begin{array}{c}\text { Eritrocytes } \\
\left(\mathrm{x} 10^{6}\right)\end{array}$ & $\mathrm{Hb}$ & $\begin{array}{c}\text { Platelet } \\
\left(\mathrm{x} 10^{3}\right)\end{array}$ \\
\hline Solvent group & $5.30 \pm 2.1$ & $6.18 \pm 2.1$ & $13.01 \pm 2.1$ & $786.66 \pm 24$ \\
DMBA group & $5.28 \pm 2.1$ & $6.12 \pm 2.1$ & $12.20 \pm 1.1$ & $562.33 \pm 25$ \\
BCS 5 preparation group & $5.63 \pm 2.1$ & $6.64 \pm 2.1$ & $13.10 \pm 3.2$ & $1011.00 \pm 31$ \\
BCS25 preparation group & $5.66 \pm 2.1$ & $6.57 \pm 2.1$ & $12.70 \pm 3.1$ & $699.33 \pm 23$ \\
BCS125 preparation group & $5.76 \pm 2.1$ & $6.46 \pm 2.1$ & $11.50 \pm 1.7$ & $845.00 \pm 34$ \\
Imboost groups & $7.40 \pm 2.1$ & $6.48 \pm 2.1$ & $13.12 \pm 4.1$ & $787.33 \pm 21$ \\
Tamoxifen group & $6.50 \pm 2.1$ & $6.49 \pm 2.1$ & $12.21 \pm 2.4$ & $837.25 \pm 22$ \\
\hline
\end{tabular}


Akrom, et al., 2019

Indones. J. Cancer Chemoprevent., 10(3), 140-148

Table 2. IFN Y secretion activity by Sprague Dawley rat lymphocytes after obtaining black cumin seed ethanolic extract for 14 days before and five weeks during DMBA-induction

\begin{tabular}{lcc}
\hline \multirow{2}{*}{ Groups } & \multicolumn{2}{c}{ IFN-ץ level (mean \pm SD) } \\
\cline { 2 - 3 } & $\begin{array}{c}\text { Before DMBA-induction } \\
\text { (two weeks) }(\mathrm{pg} / \mathrm{mL})\end{array}$ & $\begin{array}{c}\text { After DMBA-induction } \\
\text { (five weeks) }(\mathrm{pg} / \mathrm{mL})\end{array}$ \\
\hline Solvent group & $80 \pm 9.2$ & $83 \pm 10.2$ \\
DMBA group & $87 \pm 11.2$ & $72 \pm 2.7^{*}$ \\
BCS 5 preparation group & $125.4+14.3^{*}$ & $116 \pm 10.2 \mathrm{~b}$ \\
\multicolumn{1}{c}{ BCS25 preparation group } & $304+15^{*}$ & $225 \pm 18.5 \mathrm{~b}$ \\
BCS125 preparation group & $336+49^{*}$ & $690 \pm 54.1 \mathrm{a}$ \\
Imboost groups & $291.7+55^{\star}$ & $140 \pm 16.9 \mathrm{~b}$ \\
Tamoxifen group & $150+132^{*}$ & $109 \pm 89 \mathrm{~b}$ \\
\hline
\end{tabular}

note: ${ }^{*}=p<0.05$ to normal/solvent group; $a=p<0.05$ after DMBA-induction >before DMBA-induction; $b=p<0.05$ after DMBA-induction<before DMBA-induction.

\section{DISCUSSION}

DMBA induction in test animals decreases lymphocyte activity in secreting IFN- $\gamma$. The IFN- $\gamma$ secreted by the negative control group (DMBA) was the lowest. IFN- $\gamma$ level of a negative control (DMBA) was lower than the solvent group $(p<0.05)$. Administration of BCS preparations can inhibit decreased lymphocyte activity in securing IFN- $\gamma$ due to DMBA induction. In the group that had received BCS dosages of 5 and $25 \mathrm{mg} / \mathrm{kg} /$ day, imboost and tamoxifen decreased IFN $\gamma$ secretion activity due to DMBA induction, but the activity of IFN- $\gamma$ secretion by lymphocytes remained higher than the negative control group $(p<0.05)$. The group of BCS preparations with a dose of 125 $\mathrm{mg} / \mathrm{kg} \mathrm{BW} /$ day did not decrease due to DMBA induction. The level of IFN- $\gamma$ of lymphocyte culture supernatant in the BCS group dosage of $125 \mathrm{mg} /$ $\mathrm{kg} \mathrm{BW/day} \mathrm{after} \mathrm{DMBA} \mathrm{induction} \mathrm{increased} \mathrm{if}$ compared to DMBA induced $(p<0.05)$. Polycyclic aromatic hydrocarbons (PAHs) are ubiquitous environmental contaminants that are carcinogenic and immunosuppressive. Previous studies show that IP administration of DMBA to mice results in a substantial hypocellularity of the bone marrow at 48 $\mathrm{h}$ after exposure (Gao, et al., 2008). This response was dependent on local metabolism of the DMBA by Cyp1b1 that is expressed in the bone marrow, spleen, thymus, and peripheral blood leukocytes, but not the liver parenchyma (Xiao, et al., 2009) (Buters, et al., 2003). The reduction in bone marrow cellularity was evident in both the lymphoid (B cell) and myeloid (largely granulocyte) populations (Ichihara, et al., 2003; N'jai, et al., 2010). Although these previous studies identified the adverse effects of DMBA on bone marrow hematopoiesis, they did not examine whether exposure to DMBA changes the ability of lineage-specific progenitor cells to proliferate and differentiate into mature bone marrow cell populations (Gao, et al., 2008). Lymphocytes produce IFN- $\gamma$ cytokines after getting stimulation from antigens, inflammatory mediators, or other cytokines produced by macrophages or neutrophils due to antigen exposure (Upadhyay, et al., 2018). Gamma interferon plays a role in regulating natural and adaptive immune responses. IFN- $\gamma$ has been shown to inhibit carcinogenesis, neoplasm formation, and activate antitumor immunosurveillance (Selinger, et al., 2018). Thymoquinone and the active ingredient $\mathrm{BCS}$ are proven to be able to increase the activation of natural and adaptive immune responses and anti-carcinogenesis. Based on the results of this study, it is known 
that activation of the immune response by thymoquinone and BCS active substances is one of them through increased lymphocyte activity (Shaterzadeh-Yazdi, et al., 2018; Mollazadeh, et al., 2017).

\section{CONCLUSION}

From this study, it can be concluded that the administration of ethanolic extract of BCS for 14 days did not affect the peripheral blood cellular composition and the administration of BCS preparation proved to increase IFN- $\gamma$ secretion activity by lymphocytes and inhibit DMBA activity in suppressing lymphocyte activity. BCS dosages of $125 \mathrm{mg} / \mathrm{kgBW} /$ day have lymphocytes with the highest IFN- $\gamma$ secretion activity.

\section{ACKNOWLEDGMENT}

The researcher gave a thank you and appreciation to the Ministry of Technology Research and Higher Education for providing funding for the implementation of this research. This study received funding from the Ministry of Research, Technology, and Higher Education through the PTUPT research grant scheme (No grant: 227/SP2H/LT/DRPM/2019).

\section{REFERENCES}

Akrom, A. and Darmawan, E., 2017, Tolerability and safety of black cumin seed oil (Bcso) administration for 20 days in healthy subjects, Biomedical Research (India), 28(9), 4196-4201.

Akrom, A. and Mustofa, 2017, Black cumin seed oil increases phagocytic activity and secretion of $\mathrm{IL}-12$ by macrophages, Biomedical Research (India), 28(12), 5241-5245. Al-Ghamdi, M.S., 2002, The anti-inflammatory, analgesic and antipyretic activity of Nigella sativa, Journal of Ethnopharmacology, 76(1), 45-48.

American Cancer Society, 2016, Cancer Facts, Cancer Facts, 1-9.
Badr, G., Lefevre, E.A. and Mohany, M., 2011, Thymoquinone inhibits the CXCL12-induced chemotaxis of multiple myeloma cells and increases their susceptibility to fas-mediated apoptosis, PLoS ONE, 6(9).

Baj-Krzyworzeka, M., Baran, J., Szatanek, R., Stankiewicz, D., Siedlar, M. and Zembala, M., 2004, Prevention and reversal of tumor cell-induced monocyte deactivation by cytokines, purified protein derivative (PPD) and anti-IL-10 antibody, Cancer Immunity, 4, 8.

Ballestero Fêo, H., Flórez, L.M., Yamatogi, R.S., Duzanski, A.P., Araújo Jr., J.P., Oliveira, R.A. and Rocha, N.S., 2018, Does the tumour microenvironment alter tumorigenesis and clinical response in transmissible venereal tumour in dogs?, Vet Comp Oncol, 16(3), 370-378.

Barletta, E., Gorini, E., Vinels, P., Miligi, L., Davico, L., Mugnai, G., Ciolli, S., Leoni, F., Bertini, M., Matullo, G. and Costantini, A.S., 2004, Ras gene mutations in patients with acute myeloid leukemia and exposure to chemical agents, Carcinogenesis, 25(5), 749-755.

Buters, J., Quintanilla-Martinez, L., Schober, W., Soballa, V.J., Hintermair, J., Wolff, T., Gonzalez, F.J. and Greim, H., 2003, CYP1B1 determines susceptibility to low doses of 7,12-dimethylbenz[a]anthracene-induced ovarian cancers in mice: Correlation of CYP1B1-mediated DNA adducts with carcinogenicity, Carcinogenesis, 24(2), 327-334.

Castro, F., Cardoso, A.P., Gonçalves, R.M., Serre, K., and Oliveira, M.J., 2018, Interferon-gamma at the crossroads of tumor immune surveillance or evasion, Frontiers in Immunology, 9, 1-19.

Dembic, Z., 2015, The Cytokines of the Immune System: The Role of Cytokines in Disease Related to Immune Response, 1st Edition, elsevier: Academic Press.

Disis, M.L., 2010, Immune regulation of cancer, Journal of Clinical Oncology, 28(29), 4531-4538.

Dunn, G.P., Old, L.J. and Schreiber, R.D., 2004, The immunobiology of cancer immunosurveillance and immunoediting, Immunity, 21(2), 137-148. 
El-Mahmoudy, A., Matsuyama, H., Borgan, M.A., Shimizu, Y., El-Sayed, M.G., Minamoto, N. and Takewaki, T., 2002, Thymoquinone suppresses expression of inducible nitric oxide synthase in rat macrophages, International Immunopharmacology, 2(11), 1603-1611. el-Aziz, M.A., Hassan, H.A., Mohammed, M.H., Meki, A., Abdel-Ghaffar, S.K. and Hussein, M.R., 2005, The biochemical and morphological alterations following administration of melatonin, retinoic acid and Nigella sativa in mammary carcinoma:an animal model, Int. J. Exp Pathol. , 86(6), 383-396.

Fajar, D.R., Akrom and Darmawan, E., 2017, The influence of black cumin seed oil therapy with dosage of $1.5 \mathrm{~mL} /$ day and $3 \mathrm{~mL} /$ day to interleukin-21 (IL-21) expression of the patients with metabolic syndrome risk, IOP Conference Series: Materials Science and Engineering, 259(1), 012012.

Fathy, M. and Nikaido, T., 2013, In vivo modulation of iNOS pathway in hepatocellular carcinoma by Nigella sativa, Environ Health Prev Med., 18(5), 377-385.

Gao, J., Mitchell, L.A., Lauer, F.T., Burchiel, S.W., 2008, p53 and ATM/ATR regulate 7,12-dimethylbenz[a]anthracene-induced immunosuppression, Mol. Pharmacol., 73(1), 137-146.

Hayakawa, Y., Takeda, K., Yagita, H., Smyth, M.J., Van Kaer, L., Okumura, K. and Saiki, I, 2002, IFN- $\gamma$-mediated inhibition of tumor angiogenesis by natural killer T-cell ligand, a-galactosylceramide, Blood, 100(5), 1728-1733. Hidayati, T., A. (2006). Effect of ethanol extract of black cumin on phagocytic activity of macrophages of Swiss P.berghei infected mice in vitro, Proceedings of the national seminar on pharmacotherapy. Proceedings of the National Seminar on Pharmacotherapy. Yogyakarta: Professional Program of Pharmacy Faculty of UAD Pharmacy, Yogyakarta: January 14, 2006.

Hidayati, T., Akrom, Indrayanti, and Sagiran, 2017, Evaluation of the Black Cumin Seed Oil Role (BCSO) on a Decline in eNOS Expression and Plasma NO Levels: Initial Stud- ies Kemopreventive BCSO for Lung Cancer, International Journal of Bioscience, Biochemistry and Bioinformatics, 7(3), 162-168. Hidayati, T., Akrom, Indrayanti, and Sagiran, 2019, Chemopreventive effect of black cumin seed oil (BCSO) by increasing p53 expression in dimethylbenzanthracene (DMBA)-induced Sprague Dawley rats, Research Journal of Chemistry and Environment, 23(8), 24-32.

Ichihara, F., Kono, K., Takahashi, A., Kawaida, H., Sugai, H. and Fujii, H., 2003, Increased populations of regulatory $\mathrm{T}$ cells in peripheral blood and tumor-infiltrating lymphocytes in patients with gastric and esophageal cancers, Clinical Cancer Research, 9(12), 4404-4408.

Karimi, G., Aghasizadeh, M., Razavi, M. and Taghiabadi, E., 2011, Protective effects of aqueous and ethanolic extracts of Nigella sativa L. and Portulaca oleracea L. on free radical induced hemolysis of RBCs, DARU, Journal of Pharmaceutical Sciences, 19(4), 295-300.

Li, J.H., Kluger, M.S., Madge, L.A., Zheng, L., Bothwell, A.L. and Pober, J.S., 2002, Interferon- $\gamma$ augments CD95(APO-1/Fas) and pro-caspase-8 expression and sensitizes human vascular endothelial cells to CD95-mediated apoptosis, American Journal of Pathology, 161(4), 1485-1495. Mollazadeh, H., Afshari, A.R. and Hosseinzadeh, H., 2017, Review on the Potential Therapeutic Roles of Nigella sativa in the Treatment of Patients with Cancer: Involvement of Apoptosis: - Black cumin and cancer, J Pharmacopuncture, 20(3), 158-172.

Musa, D., Dilsiz, N., Gumushan, H., Ulakoglu, G. and Bitiren, M., 2004, Antitumor activity of an ethanol extract of Nigella sativa seeds, Biologia-Bratislava, 59(6), 735-740.

N'jai, A.U., Larsen, M., Shi, L., Jefcoate, C.R. and Czuprynski, C.J., 2010, Bone marrow lymphoid and myeloid progenitor cells are suppressed in 7,12-dimethylbenz(a)anthracene (DMBA) treated mice, Toxicology, 271(1-2), 27-35. Odhaib, K.J., Adeyemi, K.D., Ahmed, M.A., Jahromi, M.F., Jusoh, S., Samsudin, A.A., Ali- 
mon, A.R., Yaakub, H. and Sazili, A.Q., 2018, Influence of Nigella sativa seeds, Rosmarinus officinalis leaves and their combination on growth performance, immune response and rumen metabolism in Dorper lambs. Trop Anim Health Prod., 50(5), 1011-1023. Parmar, J., Sharma, P., Verma, P., Sharma, P. and Goyal, P.K., 2011, Modulation of DMBA- induced biochemical and histopathological changes by Syzygium cumini seed extract during skin carcinogenesis, Int J Cur Biomed Phar Res., 1(2), 24-30.

Rachman, P.N.R., Akrom, A. and Darmawan, E., 2017, The efficacy of black cumin seed (Nigella sativa) oil and hypoglycemic drug combination to reduce HbA1c level in patients with metabolic syndrome risk, IOP Conference Series: Materials Science and Engineering, 259(1), 012018.

Randhawa, M.A. and Alghamdi, M.S., 2011, Anticancer activity of Nigella sativa (Black Seed)-A review, The American Journal of Chinese Medicine, 39(6), 1075-1091.

Ren, W., Li, Y, Xia, X., Guo, W., Zhai, T., Jin, Y., Che, Y., Gao, H., Duan, X., Ma, H., Huang, T., Huang, J. and Lei, L., 2018, Arginine inhibits the malignant transformation induced by interferongamma through the NF-KB-GCN2/elF2a signaling pathway in mammary epithelial cells in vitro and in vivo, Exp Cell Res., 368(2), 236-247.

Ren, W.B., Xia, X.J., Huang, J., Guo, W.F., Che, Y.Y., Huang, T.H. and Lei, L.C., 2019, Interferon- $\gamma$ regulates cell malignant growth via the c-Abl/ HDAC2 signaling pathway in mammary epithelial cells, J Zhejiang Univ Sci B., 20(1), 39-48. Selinger, E. and Reiniš, M., 2018, Epigenetic View on Interferon $Y$ Signalling in Tumour Cells, Folia Biol., 64(4), 125-136.

Shaterzadeh-Yazdi, H., Noorbakhsh, M.F., Hayati, F., Samarghandian, S, Farkhondeh, T., 2018, Immunomodulatory and Anti-inflammatory Effects of Thymoquinone, Cardiovasc $\mathrm{He}$ matol. Disord Drug Targets., 18(1), 52-60.

Soliman, E.S., Hamad, R.T. and Ahmed, A., 2017, Prophylactic and immune modulatory influences of Nigella sativa Linn. in broilers exposed to biological challenge, Vet World, 10(12), 1447-1455.

Upadhyay, S., Sharma, N., Gupta, K.B., and Dhiman, M., 2018, Role of immune system in tumor progression and carcinogenesis, J Cell Biochem, 119(7), 5028-5042. Xiao, M., Wang, C., Zhang, J., Li, Z., Zhao, X., and Qin, Z., 2009, IFNgamma; promotes papilloma development by up-regulating th17-associated inflammation, Cancer Research, 69(5), 2010-2017.

Zekri, A.N., El Deeb, S., Bahnassy, A.A., Badr, A.M., Abdellateif, M.S., Esmat, G., Salama, H., Mohanad, M., El-Dien, A.E. and Rabah, S.A.E.A., 2018, Role of relevant immune-modulators and cytokines in hepatocellular carcinoma and premalignant hepatic lesions, World J Gastroenterol, 24(11), 1228-1238. 